\title{
NEW CHALLENGES AND OPPORTUNITIES IN LIBRARY COLLECTIONS, SERVICES, SPACES AND OPERATIONS DURING COVID-19: AN OVERVIEW
}

\author{
Sheik Maideen \\ Head Librarian, Skyline University College, UAE \\ Gmail:sheikvnr@gmail.com
}

\section{Manuscript Info}

\section{Manuscript History}

Received: 08 October 2020

Final Accepted: 22 November 2020

Published: 10 December 2020

Online Published: January 2021

DOI: http://dx.doi.org/10.35337/EIJLITR.2021.1101

Corresponding Author E-mail: sheikvnr@gmail.com (Sheik Maideen)

(C) Sheik Maideen The Author. This is an open access article under the terms of the Creative Commons Attribution License 4.0, which allows use, distribution and reproduction in any medium, provided the original work is properly cited.

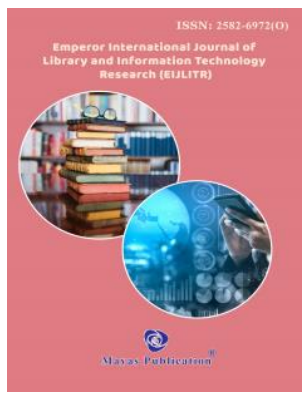

\section{Abstract}

The Corona Virus Disease 2019 (COVID-19) has changed the strategy for learning and teaching. The diverse lockdown were accounted for recalling the fleeting finish of all informational associations for by far most of the countries by the Government. As a result of these crosscountry terminations have influenced $90 \%$ of the world's graduated class understudy people. To be sure, even the school understudies are furthermore significantly affected to go to the standard classes. Preparing pros from various countries have taken various undertakings to continue with the learning cycle. Covid proposes the difference in guidance and learning into another pathway of virtual learning.

Keywords: Academic libraries, COVID-19, Library organizations in a pandemic, Virtual Learning, Reopening technique, Digital library, Massive Open Online Courses (MOOCs) AI in library organizations, etc,

\section{INTRODUCTION}

The most recent destroying pandemic condition that won in late history is the COVID-19 (UNDP, 2020). ID of the general properties of the COVID-19 may help with controlling the all-encompassing and future flare-ups of such pandemics ( $\mathrm{Li}, \mathrm{Liu}, \mathrm{Yu}$, Tang, and Tang, 2020). The consideration regarding such mainstream defilements among the general populace is totally basic (Madhav et al., 2017), especially in academic libraries where a tremendous number of allies from grouped territories are gathering. Notwithstanding the way that masters have given security evaluates, everyone will think well about the nature and technique for infection of the organism where people can be coordinated to develop their prosperity gauges properly with their specific kind of regular conditions. "Crown" is fanatically a contamination that has a spot with the Coronaviridae Family which is achieved by the pathogenic sorts of SARS-CoV, MERS-CoV and SARS-CoV-2 Coronaviruses (Li et al., 2020; Malik, 2020). There are seven such human Covids. From the outset, the SARS-CoV contamination was found in 2002 and the new Covid that returned in December 2019 in Wuhan, (Hubei, China) is known as "Genuine serious 
respiratory condition Covid 2", or SARS-CoV-2, COVID19, or crown 2 (Li et al., 2020; Malik, 2020; Valencia, 2020). It has the condition of a ("crown" in Latin is for the Crown (Valencia, 2020) or a sun fueled crown) that given by the club-formed spikes that include the outside surface of the contamination with a singular strand of RNA inside. RNA, Ribonucleic Acid is the inherited material of the contamination. CoVs diseases are around $125 \mathrm{~nm}$ in separation across (Malik, 2020). Figure 1 is depicting the graphical explanation of the new Covid.

\section{LITERATURE REVIEW}

It contains all the information to recuperate in a host body. As shown by Malik (2020), SARS-CoV and MERS-CoV are zoonotic diseases that started in bats. It was in 1960 the zoonotic Covid recognized before it perceived as a pathogenic Covid in individuals in 2002 (Malik, 2020). There is evidence that these diseases can be clear in other widely appealing has before man. Those are camels, civet cats, canines, tigers, pigs, and possibly most of the warm blooded animals and each other primate (Gollakner and Capua, 2020). In like manner, the contamination can be sent from another primate to individuals (furthermore a primate) just as human to individuals. The human transmission of the disease could provoke a scene, plague or pandemic. Malik (2020) summarized the strategy for human transmission "Human-tohuman transmission is essentially refined through close contact (inside around 3-6 feet) of respiratory dots, direct contact with the polluted individuals, or by contact with degraded articles and surfaces". It is moreover possible to get corrupted by reaching surfaces or things degraded by the contamination (Li et al., 2020; Malik, 2020; Ramesh, Siddaiah, and Joseph, 2020; WHO, 2020e). The handy contamination will remain 72 hours in treated steel and plastic surfaces (Mckeever, 2020; Valencia, 2020). Coronavirus in individuals appears as such a genuine pneumonia condition (Gollakner and Capua, 2020; Malik, 2020). Imparting the disease from a debased individual is known as "Intriguing transmission" (Malik, 2020). The disease remains in the upper respiratory package for 3 days going before the detectable quality of signs (Li et al., 2020; Malik, 2020).

There is confirmation of sending the disease to another person during this pre-demonstrative transmission period. Thusly, a spoiled individual can be a vector (transmitter of the disease) even before them observable signs. By then the contamination started to create inside the host's body and this insinuated as the bring forth time period which is 2-14 days for the Covid. (Li et al., 2020; Malik, 2020; Ramesh et al., 2020). Such patients are essentially more risky vectors. Imparting during the incubating time period is known as asymptomatic transmission (Malik, 2020). The signs of the COVID-19 viral defilement can be fever, hack, inconvenience in breathing, pneumonia, genuine extraordinary respiratory issue, a pulsating difficulty, nasal blockage, runny nose, sore throat, or detachment of the insides (Ramesh et al., 2020) Thus the strategy for viral transmission, its likely has (definitive host, widely appealing have, elective host, and unintentional hosts) will be known well. It will help the general populace with making their guarded measures while working and living. Ultimately, the pathogenicity and the investigation of sickness transmission of the zeroing in on microorganism will be known and public care should be done adequately.

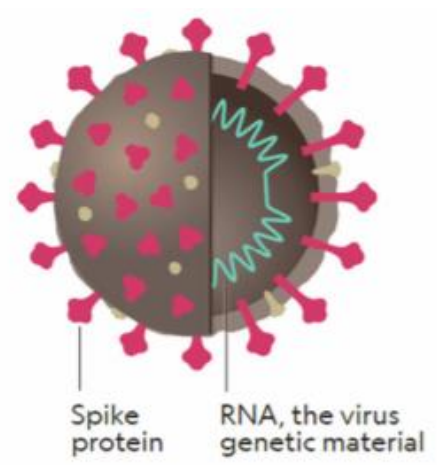

Figure 1. New coronavirus 


\section{Strategies Implemented}

Partition learning is getting more huge capacity during this pandemic. Foundations are battling to move their seminars on the web; understudies and researchers are attracting with computerized books, and electronic journals. Overall Education Coalition has dispatched by UNESCO to help countries with scaling up their best detachment learning practices as emergency responses.

In the Indian setting, the reasonably energetic National Digital Library of India (NDLI) settled at IIT Kharagpur - has set up itself the as country's greatest electronic learning stage. A head entryway to in excess of 48 million advanced books and data things across disciplines.

The World Digital Library, made by UNESCO and the Library of Congress, is an initiating attempt to develop intercultural understanding by offering induction to cutting edge inheritance from 200 countries. In India, the NDLI has begun a forceful digitization program as a group with driving inheritance reports, other than making available social messages that starting at now exist in electronic structure. It is moreover getting ready filers the country over to apply standardized 'rights explanations' to digitized social articles, to pass on their copyright and re-use status to customers.

The necessities of impeded social occasions, for instance, individuals with inadequacies must be consolidated into the very arrangement of cutting edge libraries. India's Sugamaya Pustakalaya, for example, is a pivotal online library that allows the ostensibly debilitated to get to computerized books. It is empowering that a bit of India's greater e-libraries including the NDLI are grasped to make handicap big-hearted progressions. All things considered, regardless, we need to do considerably more to make access for individuals with handicaps a reality.

The COVID-19 crisis has gone probably as an accentuation point, throwing into sharp mitigation the various preferences of cutting edge libraries. Without a doubt, mechanized libraries have displayed their normal not just to engage a more excessive, more unique public zone, anyway to propel human improvement itself.

Looking forward, we are sure that the use of e-libraries will continue growing drastically. This advancement will be driven by snappy exigencies and overall examples, for instance, the impact in PDA penetration, the extension in obligation regarding based getting contraptions, and the now gotten comfortable penchant for searching for information on the web.

\section{New Paradigm in Library Services}

Advancement takes another perspective to the extent giving the library organizations to the customers. Man-made awareness is the current advancement can be used in the library in different ways.

Man-made knowledge supports in distinctive the customers through voice, face affirmation, input the library ID, agent ID and National ID. After the unmistakable bits of verification, the applications will respond, and offer the help subject to the requesting got structure the as referenced by the customer. This is an outline of security assessment and approval. It is incredibly easy to follow, if the customer gets affected with COVID-19 through the face affirmation strategies and prevent the spread of Covid.

Man-made consciousness Chabot's: Now most of the Bank started using the AI Chabot's to handle the customer issues by throughout the day, consistently. This development plainly will improve the customer duty and augmentation the productivity for both affiliation and customer.

Robots: Robots are the remarkable decisions especially for the library and clinical fields and it will in general be used in with-in the school and outside of the school. Robots can be used in the books sterilization measure also.

\section{Drones Surveillance}

Robots will screen the customer sitting area, works out, keeping up the social partition 


\title{
Drones Services
}

Robot organizations will diminish the heaviness of the libraries and help to control the spread of the pandemic sicknesses. Quick document transport organizations is a ton of possible through robots. In fact, even robots will be more important in clinical supplies and transport the staple things.

\begin{abstract}
AI alarms
It is an AI based applications and this can be related with phones and sharp watches and it gives the caution of their plan of visiting the library organizations and it will empower the library to staff to control the customer entering and existing time. Moreover it will help the customers with booking their timings as per their advantage.
\end{abstract}

\section{AI based online tutorials}

Man-made knowledge applications will investigate the customers to find the relevant resources and organizations by partner the library online resources and it will be more valuable for the library sponsors. Online instructional activities will guide library allies to interface all the resources.

\section{Collection Development Trends}

The diminishing the essentialness of print collections.

By far most of the libraries either murder or restricted to the passageway of print collections in view of the concerns of spreading the pandemic disorders. Executives will surely stand up to the troubles in arrangement improvement approaches and make the substance on paper groupings more accessible and significant in a post-COVID-19 circumstance.

\section{Digitization and Achieves}

A huge part of the print materials are darted behind the library gateways on account of this pandemic. It underlines the Archive and digitization of print materials like the National Emergency Digital Library, and Hathi Trust opened Emergency Temporary Access to its people. At any rate the copyright issues will be a test and it should be made arrangements to advance the mass digitization endeavors through network situated limit plans and the shielding of print substance to make library print varieties more open through consortiums.

\section{Emerging E-Resources}

All through the accompanying relatively few years, library will investing extra energy and more resource for developing the electronic collections and it will be a test with diminishing monetary plans. By and by it is the ideal open door for the Libraries should detail new methodologies for exchanging better concurrences with distributers and chamber for more vital permission to streaming media and eBooks,.

The drawn out financial consequences of COVID-19, the head needs to make contracts for title-by-title purchasing that will save and decrease the expenses. Quest for extra libraries to follow and relying upon resource sharing courses of action and report transport benefits and obliging distributers to develop more open access and drop the offer plans.

\section{Prerequisite for Digitization}

The best asset of any insightful library's collection is its unprecedented arrangements and annals. Filers are facing the troubles to pass on exploration materials and organizations web during the COVID-19 end. Quest for a rise in records digitization tries in the coming years, advancing digitized content being the basic entry for the combination.

\section{Copyright Issues}

As courses go on the web, the educators need more noticeable permission to materials to use in their courses. By considering copyright act, Librarians must give more copyright tutoring, similarly as urge makers to use creative corridor licenses and entryway for more versatile copyright laws. 


\section{Self-Organization Multiplications and Virtual Decisions}

Libraries need to look for more self-organization and Touchless Associations: Self-checkout, book treats machines, channel and pass on, and materials transport. The allies won't visit the library much of the time so libraries need to offer the sorts of help to them.

Embedded librarianship. Setting overseers really in the movement of instructing and investigation attempts has been an example for a serious long time. If courses remain on the web, further joining of both library resources and staff into course the board structures is crucial to ensure understudies gain information training capacities. Overseers can assist workers with developing course content, give research gatherings, hold virtual accessible time on the web and help the distinctive verification and interfacing clearly content.

The climb of open substance: The mission for a Covid fix has emphasizd the centrality of brisk permission to legitimate information and enlightening assortments. Keepers have been lobbying for a significant long an ideal opportunity to make elective pathways for research dispersal through institutional stores and sponsorship of open-access appropriating. Quest for libraries to moreover search for more unmistakable control of the investigation being conveyed at their establishments, as can be found in the continuous climb of distributer open-access game plans.

Open enlightening resources. Libraries have quite recently played a place of expert in teaching labor force on the upsides of making and getting open educational resources, free or insignificant exertion course books, and learning materials that give teacher personalization while cutting down the cost of understudy tutoring. OERs will be mainstream as staff search for choices rather than unwieldy print course books. Libraries can in like manner familiarize and manage virtual labs with improve online understudy duty.

Support for electronic teaching. We need to fabricate further relationship with grounds working environments of internet tutoring, instructional advancement and teaching and sorting out some way to utilize this fitness and assurance that understudies and faculty have the stuff they need to win in this new online atmosphere.

Support for online assessment. Lab terminations and travel restrictions present obstructions to labor force research. Libraries can help examiners by making on the web conditions for representatives to collaborate from a decent ways. Virtual lab conditions, in light of force voice affirmation and data observation exercises, can be made to help examiners who can't lead real tests. Researchers will moreover expect spots to store data and scatter their assessment. Libraries can use instruments like ORCID to relate supported entries like ArXiv with institutional storage facilities to develop an intensive assessment stage for researchers.

The library site as a virtual front gateway. Libraries have expected to reexamine their destinations since they address the fundamental method of relationship for allies. Observing accommodation norms, look for library locales to progress to be all the more simple to utilize, responsive and versatile.

Personalization and the assurance of man-made thinking. Libraries have been reluctant to get a handle on mechanized thinking perception progressions due to our aching to make sure about the insightful chance of our promoters. Anyway AI developments could be harnessed to give more redid list things, screen social eliminating and consolidate the library into singular partners.

\section{SPACES}

\section{Studied study spaces}

Taking out tables and seats will be critical to enable social isolating. Advancement can be harnessed to help supporters with avoiding lots of individuals or recognize and book open seats in less populated districts. Quest for basic changes in space plan as libraries study customer direct and attempt to respond. 
A second, greater test exists in serving our general populations in our current impressions. Acknowledging we ought to limit the amount of supporters in our structures, more assessment spaces will be needed across grounds. Beginning to stand out in directing and arranging induction to these new spaces would allow us to end up being more joined over the geology of our establishments.

The disappearing of public development. PC labs are evaporating from our grounds, anyway libraries really have immense amounts of public PCs and extensively more essential arrangements of streaming development. Public PCs may transform into a relic of times passed by in a post-COVID-19 world. Libraries will encourage understudies to bring their own contraptions and give understudy working environments, twofold screens, shareable screens and that can be uniquely designed to particular necessities. New cleaning timetables should be made to ensure safe dispersal of advancement should that continue.

\section{Undertakings}

Delegate security. Acquisition of individual guarded stuff will be essential for laborers on the front lines to be ensured and open to interfacing with advocates. Agents may need to work in developments, making correspondence and the shielding of organization inconvenient. Office spaces should be reconsidered, also, as open-thought office spaces may offer way to deal with tendency for isolate zone.

Interminable learning and headway. The progress to work from home showed pursuing for certain people, as they were asked to quickly learn new communitarian advancements like Zoom and WebEx, Microsoft Teams, Box, and Google Docs. Most got a handle on this striking learning experience. Libraries should saddle this power, giving additional advancement getting ready and recognizing central development aptitudes for laborers in this new conventional. With development restricted, online master progression will similarly be critical.

Achieving more with less. The money related impact of COVID-19 will be felt for a serious long an ideal opportunity to come. As schools fight to keep up enrolment and reduce costs, libraries will go facing spending diminishes, enlisting freezes and other spending constraints. We will require smooth out work measures and retrain existing delegates to fill new openings. Understudy learning and labor force investigation may be influenced by what make sure to be extraordinary cuts.

Estimation of access. Covid has exacerbated the partition that exists between "essential" workers and the people who are given the upside of working from home, those with reliable web access and those without, and those whose pay or monetary prosperity don't bear the expense of them quality clinical consideration.

Clerk activism. Quest for caretakers to activate further around issues, for instance, open access, copyright, expert rights and completing the automated parcel. To prosper in this new reality, libraries should be nimbler and more responsive than any time in ongoing memory. We have learned and created during our time in segregate

\section{Information Dissemination in an ERA of a Pandemic (COVID-19): Librarians' Role}

Progressed libraries are organizations that have been made and improved for a significant long time, yet the continuous Covid-19 pandemic has made various customers aware of the organization out of the blue. Especially taking into account the finish of libraries, during the pandemic, additional undertakings have been made to progress Digital Libraries and their organizations, as undeniably perceptible and dynamic libraries. Furthermore, standard libraries or those without various progressed organizations are having the trial of sparing their organizations dynamic for their customers fundamentally during this emergency, and clerks have been participating in new work practices to achieve such objectives from their home working environments.

During the COVID-19 pandemic end, progressed libraries got restored interest, with various new customers who had the alternative to be familiar with modernized organizations. Undoubtedly, even with the continuing of libraries in the second time of COVID-19, social eliminating rules push for a 
gathering of resources on the organizations of cutting edge libraries. During the lockdown stage, the prerequisites of the organization were highlighted and these wound up going past induction to electronic resources, including such necessities as being significant for an organization, keeping up correspondence to sidestep the opinion of control, to have some great occasions and partake in activities with children and youths, support learning and training of the two understudies and teachers busy with division learning, and so on The new normal sees the need to continue offering organizations and fortifying relationship with networks by using progressed libraries and online instruments.

\section{The Present and the Future}

Making game plans for continuing of libraries is particularly trying amidst the inquiries of the procedure with pandemic. In this time, IFLA is assembling and offering induction to resources from library foundations and relationship around the globe.

With a gathering of worldwide accomplices, we are needing to propel an exceptional issue of a journal which will research the possibility of the constant change a lot and to help library specialists in illustrating their foundations' post-COVID19 indispensable organizing.

We are in like manner going after some planning materials to help caretakers with envisioning returning - watch the space and stay safe!

Organization, visiting explicitly soup kitchens and various spots where it is possible to credit endeavors to people up the creek without a paddle.

\section{REFERENCE}

1. https://www.insidehighered.com/views/2020/06/05/academic-libraries-will-changesignificant-ways-result-pandemic-opinion

2. https://www.ifla.org/covid-19-and-libraries

3. https://www.abdn.ac.uk/library/using-libraries/coronavirus-and-library-services-657.php

4. https://www.imls.gov/news/covid-19-research-partnership-inform-safe-handling-collectionsreopening-practices-libraries 